\title{
Sustainable Tropical Urbanism: Insights from Cities of the Monsoonal Asia-Pacific
}

\author{
Simona Azzali \\ https://orcid.org/0000-0003-2483-0781 \\ James Cook University, Singapore \\ Lisa Law \\ https://orcid.org/0000-0002-0095-7588 \\ James Cook University, Australia \\ Anita Lundberg \\ http://orcid.org/0000-0002-0271-4715 \\ James Cook University, Australia
}

\begin{abstract}
The Tropics is experiencing the fastest growing urbanisation on the planet and faces serious sustainability issues. This introduction to the eTropic Special Issue on 'Sustainable Tropical Urbanism' calls for a notion of plural sustainabilities in order to critique how urban sustainability has mainly been developed in temperate zones and transferred to tropical regions; but also, to recognise shared aspects of the Tropics, including climate change and environmental challenges, as well as histories of colonialism and their continuing postcolonial cultural and socioeconomic effects on peoples of the Tropics and their futures. These threads are drawn together under a conceptual trio of Place, Past, and People in order to further explore these similarities and differences. Narrowing the focus to the monsoonal AsiaPacific region, this Special Issue presents case studies from Khulna and Chittagong in Bangladesh; Singapore and the Indonesian city of Semarang in Southeast Asia; and the regional city of Cairns in tropical northeast Australia. This Special Issue of eTropic brings together research articles, scoping reviews and viewpoints from multiple disciplines and interdisciplines to explore the dynamics of sustainable tropical urbanism.
\end{abstract}

Keywords: Sustainable Tropical Urbanism; tropical cities; place-based urbanism; climate change impacts; Monsoonal Asia-Pacific

eTropic: electronic journal of studies in the tropics publishes new research from arts, humanities, social sciences and allied fields on the variety and interrelatedness of nature, culture, and society in the tropics. Published by James Cook University, a leading research institution on critical issues facing the worlds' Tropics. Free open access, Scopus Listed, Scimago Q2. Indexed in: Google Scholar, DOAJ, Crossref, Ulrich's, SHERPA/RoMEO, Pandora. ISSN 1448-2940. Creative Commons CC BY 4.0 free to download, save and reproduce. To cite, include: Author(s), Title, eTropic, volume, issue, year, pages and DOI: http://dx.doi.org/10.25120/etropic.19.2.2020.3777 
eTropic 19.2 (2020) Special Issue: Sustainable Tropical Urbanism

\section{Tropical Cities on the Rise}

I n December 2020, the world population reached 7.8 billion, a number expected to increase by 2 billion in 2050 . Of those 7.8 billion people, more than $55 \%$ live in cities, and the urbanisation process is so intense that by 2050 two-thirds of the world's population is expected to be urban. The world's urban population surpassed the rural population for the first time in 2007, representing the urbanisation of the economy and a global shift from agriculture to manufacturing, services, and finance. While cities are growing across the globe, much of the projected urban growth is expected to be in Africa and tropical Asia; the world's fastest growing cities are now in India, Nigeria and Bangladesh. All parts of the tropical world demonstrate urban intensities in unique ways: from South and Southeast Asia, to Latin America, the Caribbean, Tropical Africa, the Indian Ocean Islands, the Pacific, the Tropical North of Australia, Hawai'i and the subtropical American South. Although the future of tropical cities is diverse, malleable, and creative, it is clear that under-regulated urban growth will result in inefficient, inequitable and unsustainable urban environments. This is particularly acute for the Tropics where economic growth and population density already pose extreme threats to cultural as well as species diversities.

As tropical cities change and grow, we need commensurate changes in city planning and design, along with changes that can address the grand challenges of climate change, environmental degradation, inequality and poverty. The 2030 Agenda for Sustainable Development (United Nations, 2015a), adopted by all United Nations Member States in 2015, offers a shared 'blueprint' for peace and prosperity that is helpful for envisioning tropical cities for the future. The 17 Sustainable Development Goals (SDGs) are an "urgent call for action that recognises the intertwined goals of ending poverty, improving health and education, reducing inequality, and enabling sustainable economic growth - all the while tackling climate change and working to preserve our oceans and forests" (United Nations, 2015b). Goal 11 Sustainable Cities and Communities is of particular relevance to envisioning sustainable cities in the Tropics, although the authors in this Special Issue also speak to Goal 3 Good Health and Wellbeing (Yew, 2020), Goal 8 Decent Work and Economic Growth (Chaiechi et al., 2020; Lundberg \& Peer, 2020), Goal 12 Sustainable Consumption and Production (Wood et al., 2020), Goal 13 Climate Action (Law \& Musso, 2020; Yulia \& Arlianda, 2020; Al Mamun et al., 2020) and Goal 17 Partnerships for the Goals (Yulia \& Arlianda, 2020). A more specifically urban vision is in the United Nations' New Urban Agenda: "a shared vision for a better and more sustainable future. If well-planned and wellmanaged, urbanization can be a powerful tool for sustainable development for both 
eTropic 19.2 (2020) Special Issue: Sustainable Tropical Urbanism

developing and developed countries" (2017). The world is now entering the Decade of Action to deliver the Sustainable Development Goals by 2030, but it is difficult for national governments to mandate what effectively requires place-based solutions, robust local governance and authentic grassroots participation. The United Nations just delivered a World Cities Report 2020: The Value of Sustainable Urbanization (UNHabitat, 2020), which provides further justification for progressive urban governance. But the challenges of sustainable urbanisation in the tropical world require more than Goals and Frameworks, and trenchant critiques point to their Euro-American roots and neoliberal tendencies, as well as their limited ability for emancipatory politics and transformation (Amin, 2006; Sultana, 2018).

This Special Issue on Sustainable Tropical Urbanism calls for a notion of plural sustainabilities as a shared critique that understands urban sustainability as a discourse emerging in temperate zones but circulating to tropical regions in distinct ways. Tropical urban sustainability calls for a recognition of shared histories and future prospects for the Tropics, including histories of colonialism(s) with their enduring cultural and economic influences. It also calls for recognition of already existing urban sustainabilities in tropical cities, where the modern hyper-separation of economies, ecologies and urban infrastructure has not been seamless or complete (GibsonGraham et al., 2016), and where many urban residents still consume far less energy and resources than urban residents in the Global North. Moreover, Sustainable Tropical Urbanism reminds us of the significance of climates and environments in the anthropocene, and the need for shared practices of tropical urban sustainability between regions, nations and peoples of the tropics.

Yet plural sustainabilities also alert us to the complexity of the Tropics itself which shares similarities and differences across various tropical geographic regions - as well as within regions. We explore these complexities by focusing this Special Issue on cities in the 'Monsoonal Asia-Pacific'. This allows us to explore the shared experience of a "climatic system in which large scale winds bring distinct seasons of wet and dry weather", while at the same time considering the kinds of built environments that have evolved "in symbiosis with the temporality, excesses and scarcities this weather system brings" (Gibson et al., 2018, p 2). An environmental focus is particularly relevant in the context of climate uncertainty, but also allows us to connect places usually associated with the Global North (Cairns) to tropical Asia where a shared weather system shapes architecture and urban design repertoires that have evolved over time to address seasonal rains, humidity and heat avoidance, as well as tropical cyclones/typhoons. Indeed, Australia's northern tropical monsoon zone suffers from a culture of governance from the temperate southern area of Australia, under which heat 
eTropic 19.2 (2020) Special Issue: Sustainable Tropical Urbanism

is measured and managed without due consideration of the affordances of a tropical climate (Opperman et al., 2017). And while 'tropical climate' is one of the five major climate groups in the Köppen climate classification, it is also important that this tropical designation is further divided into tropical rainforest, tropical monsoon and tropical savanna climates. This Special Issue covers these distinct zones, which all yield further specificities in terms of design response, but our emphasis on the larger monsoonal weather system reflects our desire to share knowledge across these networks.

The papers collected in this Special Issue also provide a voyage through time from deltaic cities of Bangladesh where colonial architecture was adapted to tropical weather and water landscapes, to wartime industrial heritage set in a tropical rainforest in the far northeast of Australia, to contemporary international and interdisciplinary collaborations for climate change policy in Semarang, Indonesia, and finally to the postcolonial island metropolis of Singapore where urban development, planning and nation building entwine to address futuristic projects in land reclamation, vertical food production, and sustainable living for an aging population.

Thus the introduction to this Special Issue aims to accompany the reader on a voyage to specific places at various periods of time to encounter peopled cities and their unique tropical environments, including: colonial architecture, passive design techniques and urban water landscapes; industrial heritage and the role of community arts in place making; climate change policy transfer; urban design and economic growth; land reclamation, sand consumption and migrant labour; as well as unveil future prospects in tropical living, such as vertical farming techniques and new forms of planning to address an aging population. While each contribution covers a specific aspect of sustainability and many address climate concerns, what we propose is a conceptual framework which gathers those multiple situations into three overlapping perspectives of Place, Past, and People (see Figure 1 below). As with a kaleidoscope, in which the reflection of a particular object can reveal numerous patterns according to how we adjust the viewing device, our conceptual trio brings to light a plurality of tropical sustainabilities, each one revealing nuances and differences, but also reflecting a shared background - that of the Tropics and specifically the monsoonal Asia-Pacific. 
eTropic 19.2 (2020) Special Issue: Sustainable Tropical Urbanism

Figure 1. Sustainable Tropical Urbanism: Place, Past, People

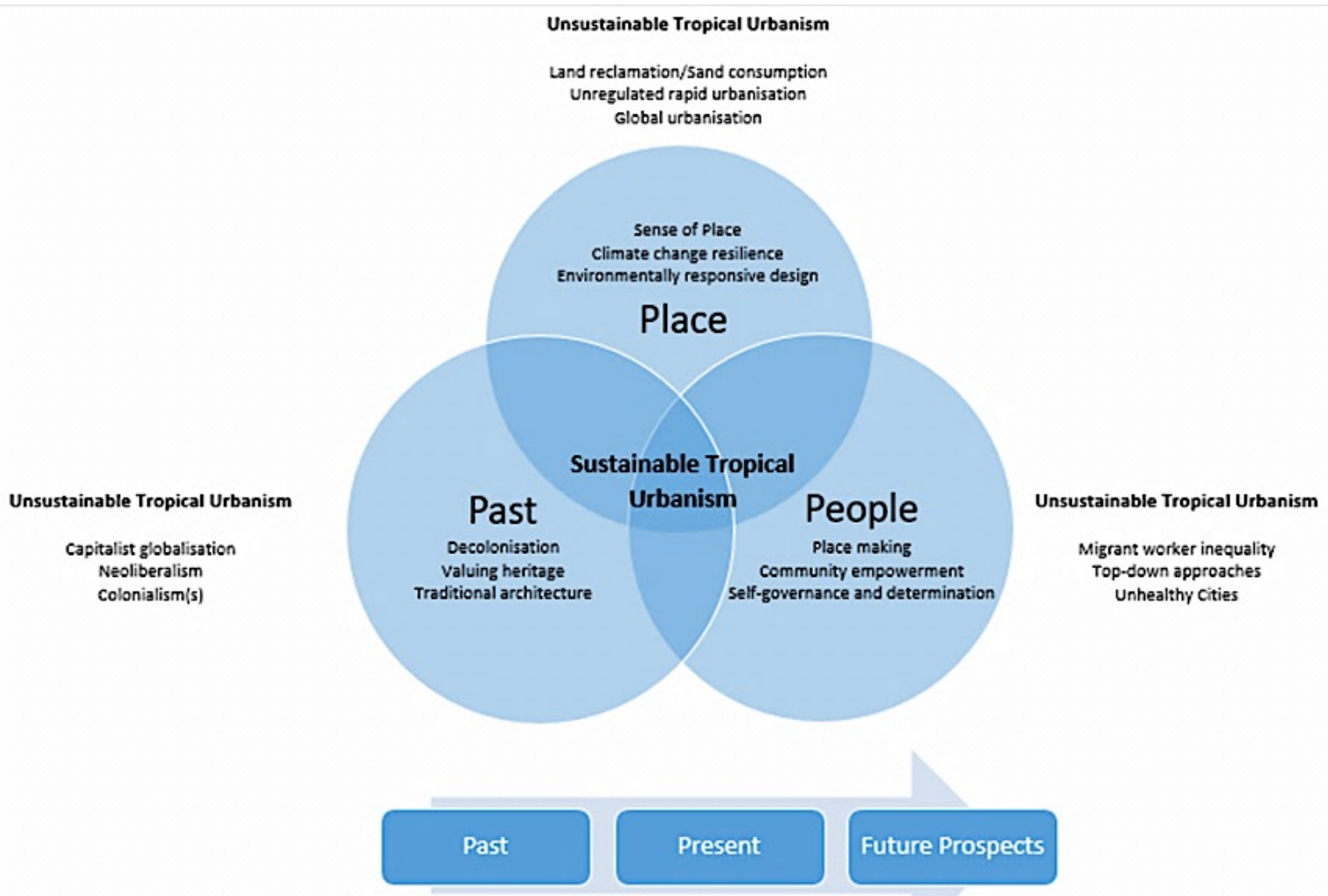

\section{PLACE: Changing Urban Environments of the Monsoonal Asia-Pacific}

Place is a combination of climate, environment, lifestyles and the meanings people attach to their environments (Law \& Musso, 2020; Law et al., in press). If we posit an environmental 'sense of place' for the Tropics, it would relate to this fusion of environmental and cultural elements, where wind, rain, heat and humidity inspire unique built landscapes that reflect, but also help to shape, distinctive ways of living. The narrow Longhouses of Borneo, with open sides for maximum cross-ventilation, and deep overhangs for sun and rain protection, provide flexible spatial planning for communal living arrangements. The high set Queenslander, built on stilts/stumps, counteracts flooding, draws cooler air up from beneath the house through open floor boards, and provides a sheltered work space underneath, and wide verandahs for family life. These environmentally sensitive design features worked in symbiosis with place and were constructed out of locally grown, lightweight materials that produced porous building envelopes enabling air flow. These materials have slowly been 'modernised' and replaced; with wood, bamboo and thatch giving way to corrugated iron, steel, bricks and concrete. Urban consolidation has also encouraged land 
eTropic 19.2 (2020) Special Issue: Sustainable Tropical Urbanism

reclamation and higher urban densities, often without a consideration of breezeway or green space provision to cool the urban environment, and much of the new infrastructure is energy-hungry (Giridharana and Emmanuel, 2018; Safarova et al., 2018). Urban heat islands in the tropics are dangerous precedents in a context of global warming in already hot cities. The mitigation of urban heat through urban design practice is an urgent agenda for tropical cities.

The integration of nature in the built environment is a key concern of sustainable urbanism, not just in terms of embodied architecture but also in the wider urban framework and design of cities. On the one hand, green and blue-green infrastructure is a key component for providing ecosystem services, mediating urban microclimates and fostering disaster resilience in tropical cities (Song et al., 2018; Lindley et al., 2018). Several studies have shown that proximity of green spaces and parks to housing facilitate community interaction, well-being, and satisfaction, which helps to counteract urbanisation's direct link with a rise in mental and behavioural disorders, increasing social isolation, and the increased prevalence of lifestyle-related diseases, including hypertension, diabetes, and obesity (Nutsford et al., 2017). On the other hand, despite the overwhelming evidence pointing to the existence and severity of climate change, governments have largely failed to deliver on obligations to their communities to adequately respond and prepare them.

Although a global phenomenon, climate change has specific effects within the Tropics. In the tropical Asia-Pacific which spans South Asia, Southeast Asia and Oceania, rising sea levels are predicted to be higher than the global average and are further impacted by the atmospheric systems of the Indian Ocean Dipole (IOD) and the El Niño-Southern Oscillation (ENSO), which involves both El Niño and La Niña events. Of concern is the predicted increase in frequencies and intensities of oceanicatmospheric phenomena as a consequence of global warming which alter weather patterns around the tropics and subtropics, leading to extreme rainfall in some regions and drought in others (Lundberg, 2020; Lundberg \& Peer, 2020, p. 220). These differential impacts suggest the need for a more nuanced and plural concept of sustainability and for articulations towards a concept of tropical sustainability that includes the sharing of knowledge between cities and regions experiencing common climatic impacts (Yulia \& Arlianda, 2020). As Chaiechi (2020) suggests, climate classifications and geography matter for advancing urban sustainability research. Innovative, multidisciplinary approaches are required.

The papers in this collection speak of issues pertaining to specific cities with a geographic range across the monsoonal Asia-Pacific: from Khulna and Chittagong in Bangladesh; to Singapore and the Indonesian city of Semarang in Southeast Asia, and then to the regional city of Cairns in the far northeast of Australia. These cities are 
eTropic 19.2 (2020) Special Issue: Sustainable Tropical Urbanism

located across a vast region and are impacted by climate change in specific ways, yet also share common climatic concerns. The issue of global warming impacts all these tropical cities, however this is not to imply that these instances of urban warming are uniform. While Singapore, which lies just above the Equator, and Semarang a city below the Equator on the Island of Java, experience year round hot temperatures, the Bangladesh cities of Khulna and Chittagong near the Tropic of Cancer and Cairns in far north Australia, experience long hot summers and pleasant cooler periods. All the cities investigated in this Special Issue have significant wet seasons, but can also be affected by droughts. Likewise, each is connected to water. Khulna is a river port city, while Chittagong, Singapore, Semarang and Cairns are coastal port cities. Furthermore, Khulna and Chittagong are in the Bengal delta, which, along with the island of Singapore and the lowlands of Semarang, are feeling the impacts of rising sea levels. Singapore and Semarang are also prone to inundation due to sea storm surges as an aspect of rising sea levels; while Chittagong and Cairns lie in major tropical storm paths and are thus vulnerable to changes in climate atmospherics and increasing intensities of cyclones. Building sustainable and resilient cities in the monsoonal zone requires a shared knowledge of urban design mitigation strategies.

\section{PAST: Legacies of Colonialism and Governance from Elsewhere}

The notion of tropical urban sustainability also extends beyond climatic considerations. There is the need within urban sustainability to address knowledge and experiences of shared pasts as these affect present concerns and future prospects. In this regard a notion of tropical sustainability is pertinent as the tropical zone has been historically most strongly impacted by colonialism(s). Again it is important to note that colonialism involves both shared, as well as specific cultural, economic and environmental effects according to colonising/colonised geographies. For instance, in the Asia-Pacific during the colonial period local cultures and places came under British, Dutch, Spanish, Portuguese, French or American rule (and many under several waves of colonisation by various of these different rulers), as well as Japanese occupation during World War II which corresponded with the end of the colonial period. Most countries of the AsiaPacific continue to work towards developing postcolonial identities - which often include creating awareness of, and conserving, urban and architectural legacies of colonial pasts (Islam \& Muntasir, 2020; Al Mamun et al., 2020), and re-imagining them into postcolonial futures. In the cities presented in this collection it is the impacts of British and Dutch colonial periods which continue to have presence, including in the siting of cities, urban design layout and heritage buildings.

On the one hand, built landscape is an expression of 'civilisation', and monuments and old buildings are symbols of civic, moral, and religious values. A sustainable urban design approach should look at the existing urban fabric, using a methodology centred 
eTropic 19.2 (2020) Special Issue: Sustainable Tropical Urbanism

on the interpretation of the pre-existent context; the old urban fabric in this sense is a source of generative ideas and design principles, which are embedded into the historical layering of design concepts (Petruccioli, 2007; Furlan \& Petruccioli, 2016). Understanding history, and analysing past experiences and precedents not only provides a larger perspective but can lead to a better understanding of a problem with new ideas for potential solutions (Azzali, 2019). On the other hand, for tropical cities, sustainability dynamics are messy and about power and histories of governance from elsewhere. In this sense, the dynamic of time (past, present, and future prospects) is important to understanding the papers in this Special Issue. The tropical city is in many ways a story of the colonial tropical city - whether that be adapting colonial architecture to tropical weather (Islam \& Muntasir, 2020), or planning for the postcolonial tropical city of the future and its need to produce its own food (Wood et al., 2020) and to prepare for generations of aging populations (Yew, 2020). Al Mamum et al.'s (2020) contribution offers an example of this dilemma as it explores the relationship of built heritage with the water-edge urban structure and water landscape, supporting the idea that incorporating lessons of urban history could become a sustainable tool to preserve urban heritage and city revitalisation.

\section{PEOPLE: People-Centred Approaches for Tropical Sustainable Cities}

Designing tropical cities for the future requires a focus on people: tropical urban planning should be people-oriented and community-centric. To paraphrase Jan Gehl (2010), cities should be for people, with their experiences of the urban landscape a priority. But while we must learn from people we also have to empower local communities. Indeed, all members of the community require some level of awareness through inclusive education, training and capacity building. Participation processes allow for community education about poorly understood problems and policy issues, which builds understanding and incentives for collaboration (Burby, 2007) thus improving local communities' self-reliance, social justice, and participatory decisionmaking. Broad public involvement creates the potential to expand understanding of problems and to develop a stronger set of policies for dealing with them. However, urban tropical sustainability also needs to include policy transfer and capacity building frameworks. Due to a specific focus on the monsoonal Asia-Pacific the papers collected in this Special Issue are also able to demonstrate the importance of shared knowledge and how this is articulated between people. One of the emphases of a regional tropical sustainability is this people focus with the potential to share urban sustainability knowledge expressly of the tropics between urban designers (as argued in the paper by Yulia \& Arlianda, 2020), between planners and architects working in heritage, as well as between urban developers, architects, heritage consultants and community members (Castles, 2020; Islam \& Muntasir, 2020). Another aspect of this peopled approach and sharing of knowledge is the need to consider the labour that 
eTropic 19.2 (2020) Special Issue: Sustainable Tropical Urbanism

builds cities, and expressly cartographies of migrant labour which map the flows of people around the Asia-Pacific region and chart economies of inequality. In this sense, Lundberg and Peer (2020) offer a critique of Singapore's treatment of migrant workers as it constructs the imaginary of the 'Singapore Dream'.

Importantly a tropical urban sustainability would offer the potential to explore tropical senses of place. The Tropics is not merely a space that lies between the Tropics of Capricorn and Cancer - it is redolent with legacies of the past, and is mapped with movements of peoples and cultures. Similarly, cities are not just cartographic pinpoints, they are alive and lived through people. Humans create cities, urban design and policies need to include people, and cities are born through the labour of people "we need a renewed, people-centric conception of the city" (Lundberg, 2018, p.5).

\section{Travelling through Reading: The Sustainable Tropical Urbanism Papers}

Each of the papers brought together in this Special Issue address the dynamics of the Tropics and tropical sustainabilities, and read as a collection, take the reader on a voyage to understand particular tropical influences on specific urban sustainabilities. The first paper undertakes a scoping review of literature which reveals the lack of, and urgent need for, multidisciplinary studies in urban sustainability within the geographical zone of the Tropics, while the papers that follow it each undertake a study of a topic within a cityscape, or through a comparison of cities, within the monsoonal AsiaPacific. The papers are informed by different theoretical and methodological approaches, many are researched and written by multidisciplinary teams, and several are interdisciplinary. While some papers address sustainability as a focal concern, others turn their kaleidoscope to climate change as an underlying issue, or to the revitalisation of heritage architecture - colonial or industrial - as fundamental to a sense of place within a tropical landscape. Like a kaleidoscope, the theoretical and methodological perspectives of these papers offer a variety of viewpoints into the issue of tropical sustainability, including: a scoping review, urban design and planning perspectives, heritage urban design and architecture, policy analysis and policy transfer, urban socioeconomic development and urban film ethnography.

\section{Sustainable Tropical Cities - Scoping Review}

This Special Issue of eTropic opens with Taha Chaiechi's paper "Sustainable Tropical Cities: A Scoping Review of Multidisciplinary Methods for Urban Planning" (2020) as the author articulates a gap in knowledge regarding studies in urban sustainability methods. She notes that most studies employ traditionally narrow disciplinary approaches while also reducing their focus to concentrate solely on issues of environmental sustainability. This neglects wider issues pertinent to sustainable 
eTropic 19.2 (2020) Special Issue: Sustainable Tropical Urbanism

knowledge which necessitate multidisciplinary perspectives in order to understand and articulate how the intertwining of climatic, geographic and socio-cultural factors are critical to sustainable urban planning.

Adopting a scoping review methodology, the paper maps the literature across a wide range of studies to provide an overview of existing research and identify key methodologies. The scoping review further uncovers the need for an enhanced understanding of the interconnections between sustainable cities and development, and further for the incorporation of sociocultural, economic and environmental-climatic factors into sustainable urban models and planning policies. Globally, although methodological diversity of studies in urbanism has been expanding due to the growing interest from various academic disciplines, there remains a continued requirement for sustainable urban planning through innovative multidisciplinary approaches. While researchers acknowledge the multidisciplinary nature of sustainability research, discussions of appropriate methodologies for understanding sustainable city growth remain fragmented and lack interdisciplinary perspectives. There is also a lack of multidisciplinary and interdisciplinary frameworks to assess practical methods for urban sustainability. The paper calls for accelerated knowledge creation in the field of urban development based on climate-classifications, socioeconomic information, and locational characteristics. It particularly notes the need for research in the Tropics where distinct climatic and socio-economic dynamics have specific impacts on sustainable urban planning. The results of the scoping review revealed that of the 38 countries covered in the study, a majority 21 countries were located in temperate and frigid zones, 7 of the temperate zone countries were partly situated in the subtropical zone, 5 countries were located in the broad region of subtropical and tropical zones, and only 5 countries were totally located within the tropics. Chaiechi notes that even though urban sustainability studies are increasing in the literature as a result of urgent interest, and diversification in methodological approaches; the scoping review exposes a lack of well-developed methods that focus on the Tropics. Chaiechi argues that this is significant as climatic and geographic aspects influence the characteristics of urban systems. Furthermore, cities within tropical zones face specific challenges posed by hot and humid conditions, and by climate change. The paper calls for accelerated multidisciplinary research in the field of tropical city sustainability.

\section{Towards a Tropical Urbanism - Cairns}

The second paper of this Special Issue moves from the previous paper's discussion of the Tropics as a space encircling the globe, to draw the reader to the tropical AsiaPacific region of far north Australia and into a study involving multidisciplinary perspectives as they are employed in understanding how climatic, geographic and 
eTropic 19.2 (2020) Special Issue: Sustainable Tropical Urbanism

sociocultural factors pertain to sustainable urban planning. In this second paper entitled "Towards a Tropical Urbanism for Cairns, Australia," Lisa Law and Urbi Musso (2020) take us to Cairns, a tourist dependent coastal city located in far north Queensland between the UNESCO World Heritage sites of the the Wet Tropics rainforest and the Great Barrier Reef. The authors outline how the term Tropical Urbanism first arose in 2010 and 2011 in two local government master plans, and again in 2016 in the city's local government planning scheme. This concept of Tropical Urbanism invigorated discussions regarding the framing of the tropical climate within urban planning and an integration of sustainability and environmental sensitive practices, as well as spurring a revitalised emphasis on lifestyle and cultural considerations. The authors note the growing need for effective urban design that addresses tropical climates - including responsiveness to regional specificities. In the context of Cairns, they address how this agenda involves the local government as well as developers, architects and the tourism industry. To rearticulate their analysis, this is suggestive of how a recognition of tropical climate ipso facto has persuasive effects, "encouraging a range of professionals to think across all scales of tropical urban design, not just the architecture of individual buildings" (Law \& Musso, 2020, p.53).

Law and Musso explain how the term Tropical Urbanism is an environmental and sociocultural designation that encapsulates climate, lifestyle patterns and urban identity as constitutive of the city. They further argue that the climatic-environmental awareness inscribed within the term Tropical Urbanism positions it as a more sensitive and distinctive language of urban design than the concept of New Urbanism - and one that is particularly applicable for far-flung cities in the regional areas of tropical Australia. Law and Musso undertake an in-depth reading of the Cairns local government 2010/2011 master plans and the 2016 planning scheme provision and how they explicitly address the tropical climate of the regional city. They compliment this analysis with observations and quotations from interviews conducted with Cairnsbased city planners and architects. Although their analysis demonstrates and acknowledges the importance of local place-based urban plan initiatives to the sustainability of regional cities - and the sustainability of design outcomes - they evaluate the need for a more progressive Tropical Urbanism which could be achieved through the incorporation of a Critical Regionalist approach that more explicitly recognises social, cultural, Indigenous and sociopolitical concerns.

\section{Colonial Heritage Buildings in a Deltaic Landscape - Khulna}

Reading the third paper in this collection takes us back in time to the Colonial period and across the Bengal deltaic landscapes, to the city of Khulna. In their paper, "Tropicality of Colonial Heritage Buildings in a Deltaic Landscape: British Colonial Architecture in Khulna", Muhaiminul Islam and Hasan Muntasir (2020) propose that 
eTropic 19.2 (2020) Special Issue: Sustainable Tropical Urbanism

the roots of tropical architecture are to be found in the colonial period. As they explain, "tropicalized" architecture has been noted from the 1820s (Islam \& Muntasir 2020, p. 73) long before it became institutionalised as an architectural body of knowledge in temperate countries, where it was then taught to students of newly decolonised tropical countries who journeyed to the metropole (or other Anglo countries) to study architecture, and returned bringing this institutionalised tropical design knowledge back to their home countries.

Climate was the raisons d'être for tropical architecture during colonialism, and the following decolonisation and the postcolonial periods. As Islam and Muntasir note, European buildings were unsuited to the climate of their various tropical regions, with warm and hot temperatures cited as a major problem for Anglo-European architecture in the tropics. Tropical architecture was thus a direct response to tropical climates and was instigated through adaptations of architectural elements of colonial buildings including the addition of verandahs and shading devices. They articulate how the British strove to visually embody imperial power into their buildings, and in the Indian subcontinent this was achieved by mixing imperial grandness with traditional architecture and climate considerations to produce the Indo-Gothic or Indo-Saracenic style which mixed elements from previous empires, including classic European and Mughal. However, in the Bengal deltaic region this empire style was less practiced due to the monsoon climate and water environment. Instead, details and local motifs were incorporated into colonial buildings; with this process acting to contextualise British power stylistically, while emotionally appealing to locals. Their paper undertakes a detailed examination of four colonial buildings in the city of Khulna. The buildings' climate adaptation features were analysed in order to reveal their significant tropical architectural features which increase ventilation and air flow, and inhibit problems of solar radiation, humidity and driving rain. Importantly, this paper is not just about the past; present day Khulna is witnessing the demolition of large numbers of colonial buildings under the pressures of rapid urban growth - including population pressures due to climate change migrants from surrounding rural areas - and there is a lack of heritage and environmental conservation and protection. The study demonstrates how to identify the architectural and environmental knowledge that is embedded within colonial buildings which is essential for heritage conservation, and the paper further offers a reinvigoration in conceptualising climate responsiveness for contemporary buildings in deltaic Bangladesh. Islam and Muntasir, as they state at the outset of their paper, aim to inspire practicing tropical architects by showcasing heritage buildings and "revealing how, a century ago, colonial buildings were influenced by the tropical deltaic climate, which impacted foreign architectural ideology and practice" (Islam \& Muntasir, 2020, p. 72). 
eTropic 19.2 (2020) Special Issue: Sustainable Tropical Urbanism

\section{Urban Heritage and Sustainable Water-Edge Design - Chittagong}

The fourth paper continues an exploration of the Bengal delta moving us to the city of Chittagong. Mustiafiz Al Mamun, Pranjib Paul, Sadman Noor and Anjuman Ara Begum's paper "Reviving the Urban Water-Edge: History and Heritage Morphology in the Envisaging of Chittagong City" (2020) argues that in tropical Asia, many ancient cities embodied the example of urban settlements along waterways. Water held ritual significance, provided sustainable living, and was important to trade economies. However, due to rapid increases in urban population, economic expansion, and modern infrastructure, many cities moved their business districts away from traditional waterfront locations. In Chittagong, these changes in urbanisation have led to the neglect of its waterways causing severe water pollution, interrupted water drainage, waterlogging, and flash floods. The deterioration of waterfronts has furthermore resulted in challenges in the identification of urban morphological patterns and heritage structures, which impede heritage conservation and preservation efforts of buildings that are of significance to the cultural identity of the city. As the authors argue: "past heritage can provide a wider sense of social belonging and identity which is not isolated to a building but incorporates the site's social, cultural, economic and environmental surroundings" (Al Mamun et al., 2020, p. 98). The rising significance of heritage has until recently overlooked the complex qualities of historic water-edge built environments. The authors note that the relationship of built heritage with the wateredge, urban structure and water landscape incorporating lessons of urban history, could become a sustainable tool to preserve urban heritage and, furthermore, requires research into integrating past and present built environments for the revival of waterfronts for the city's future prospects. This, they argue, will necessitate a contextual design approach, a return to an architectural philosophy that is capable of reflecting on senses of place.

Chittagong is an ancient port city situated on the Bay of Bengal with a history spanning several empires, including Munghal and Sultani, as well as British colonialism. The city has a significant deltaic water environment of rivers and canals and is experiencing climate change effects including susceptibility to flooding and increased intensities of tropical cyclones. The authors note that waterways are not only important for urban geographical environments but because they influence and confine their surrounding urban morphology they also perform a vital role in the shaping of societies and their economic growth. Urban morphology is an important approach as it considers heritage buildings within the urban landscape while incorporating insights from urban history. This approach is also culturally sensitive and embodies a local sense of belonging, further enhancing a sustainable approach for redevelopment. The authors employed a mixed-methods approach with evidence collected from documents, expert opinion, and local knowledge. The historical existence of Chittagong city within its landscape 
eTropic 19.2 (2020) Special Issue: Sustainable Tropical Urbanism

of historical structures near prominent waterfronts was examined through a process of historical coding and urban morphological coding in order to establish the relationship between architectural characteristics of selected heritage buildings and their urban waterfronts. Coding included ground plans, building fabric and site and building utilisation. A selection of scientific articles explicitly examining the role of the waterfront were analysed in order to ascertain the important connectivity between buildings and water. Insensitive development along waterways and interrupted visual connectivity between the traditional buildings and the water-edge was found to be a major impediment to demonstrating the past quotidian significance of these buildings and thus proving the buildings' heritage importance in order to enact their conservation and, or, preservation. The authors argue that a sensitive water-edge regeneration can positively impact local businesses and trade while enriching the urban landscape. The research concludes that there is an urgent need for sustainable revitalisation of waterfront spaces in the (re)envisaging of Chittagong city.

\section{Industrial Heritage Adaptive Reuse for Culture and the Arts - Cairns}

From investigations of colonial heritage, we move to the fifth paper in this Special Issue which introduces the reader to industrial heritage from World War II and takes us from Bengal deltaic landscapes to the wet tropics of northeast Australia. In his article "Community Initiated Adaptive Reuse for Culture and the Arts: 'The Tanks Arts Centre', Cairns, Australia," Anthony Castles (2020) discusses industrial heritage, artsled regeneration processes, and community participation. Castles shows us how a group of naval fuel storage tanks strategically located in a rainforest during World War II have become an important site for culture and the arts in Cairns. He analyses how community attachment to the site grew, not through top-down planning, but through a community-initiated approach to reimagine the site's reuse. Castles shares his insider perspective, having worked as an employee of The Tanks Arts Centre and witnessing how the community and performing artists developed and maintained strong affective attachment to the site over time. He combines this insight with a scoping review, secondary data and semi-structured interviews with key industry stakeholders to explore the importance of the city's past to reimagining its future. Industrial heritage can offer tropical cities unique ways to not only revive their urban landscapes but to encourage new investment, and restore local senses of place.

The Tanks Arts Centre is a compelling case study. It showcases a successful example of a long abandoned industrial site adapted into an attractive and unusual arts centre without compromising its value as a World War II industrial relic. It maintains a tropical gothic aesthetic that works with the site. Castles demonstrates how this evolved through local drive, passion and imagination. Local governments often encourage feedback from the community to develop community infrastructure projects, and 
eTropic 19.2 (2020) Special Issue: Sustainable Tropical Urbanism

Castles explores how the Cairns City Council engaged and consulted with the community regarding the reuse of the Tanks Arts Centre in the 1990s. Continued programming support since the 1990s has ensured the Tanks' vitality and relevance. The success of arts and cultural precincts relies on consulting and meeting with the general community and arts stakeholders to ensure the reuse of the heritage place meets the larger region's social, cultural and economic agendas. This approach to heritage is important for many cities in the Tropics, as many urban areas were built during a time of industrial expansion. Castles' shows how even the most unusual industrial sites can become meaningful places for local communities.

\section{Climate Resilience and Policy Transfer - Semarang}

While the previous paper highlights the importance of stakeholder consultation and good governance at the local city level in tropical Australia, the sixth paper reiterates the significance of consultative processes at the international level in relation to mitigating and adapting to climate change on the densely populated Island of Java in Indonesia. Unregulated urbanisation results in deforestation, habitat destruction and increased greenhouse gas emissions. Poorly planned, sprawling cities also mean overcrowding in areas most vulnerable to environmental shocks such as flooding and landslides - thus accelerating the impacts of climate change on a city's poor and vulnerable people. Improving climate resilience involves assessing how climate change will create new, or alter current, climate-related risks, and taking steps to better cope with these risks. Capacity building is an essential component of climate change adaptation initiatives, as are developing collaborations that enable cities to learn best practices and strategies from other cities in cross-regional and global networks.

In their paper "Climate Resilience and Policy Transfer in Semarang City, Indonesia", Yulia Yulia and Reza Arlianda (2020) explore the benefits of sharing climate change policies in Semarang. The authors identify the city as a pertinent study "due to its hydro-meteorological issues affected by both global and tropical Asia-Pacific climate change phenomena and its coastal and riverine geography" (2020, p. 145). Semarang is a coastal port city surrounded by hills which suffer landslides, and low lying areas inundated by tidal and flash floods. The city is already impacted by sea level rise, land subsidence and coastal erosion, but urban growth is amplifying these problems, making it even more vulnerable to the impacts of climate change. The Semarang City Government has been proactive and sought collaborations with national and international partners to mitigate and adapt to these changes, and Yulia and Arlianda examine Semarang's participation in two international networks: '100 Resilient Cities', a global network involving 100 cities from various world regions; and 'Water as Leverage' which comprised an inter-regional network of three selected cities in the monsoonal Asia-Pacific: Semarang, Indonesia; Chennai in Tamil Nadu, India; and 
eTropic 19.2 (2020) Special Issue: Sustainable Tropical Urbanism

Khulna, Bangladesh. The authors explore the advantages and challenges of city-tocity collaboration and policy transfer through interviews with key stakeholders from these two programs. They furthermore define a policy transfer framework that helps evaluate the success of climate change policy transfer and identify key success factors, including the importance of local initiation and motivation that can act as a driver for the policy. Significantly, the authors note that a successful policy transfer process necessitates "a process of transformation, including in ways of thinking, planning customs and problem-solving. Such transformations are not possible under short time constraints, thus duration and continuity play an important role in policy transfer processes" $(2020$, p. 167). Their research shows that any city considering a policy transfer process should have the following minimum preconditions: good international portfolios, good governance, solid local stakeholders' collaboration, and a shared understanding of the relevant issues and challenges.

\section{Urban Design and Economic Growth - Cairns and Singapore}

Policies for urban growth and management shape disaster resilience; they also shape pathways for a city's economic development. While urbanisation can improve economic growth, rapid urbanisation can negatively impact the economy via its effect on straining infrastructures. In their article "Urban Design and Economic Growth: An Analytical Tale of Two Tropical Cities", Taha Chaiechi, Caroline Wong and Silvia Tavares (2020) shed light on the relationship between economic and urban growth patterns. They investigate the relationship between economic growth and indicators of urbanisation by revisiting familiar urban typologies from an urban growth perspective, namely the Concentric Circle Growth (CCG) model, Axial Growth model, Sector Growth model, and Multiple Nuclei Growth (MNG) model. Of particular interest is the MNG model, where a city develops around a Central Business District and expands outward, a multiple-nuclei structure emerges giving life to new regional areas dedicated to different business activities and land uses including residential, commercial, and education, or special uses such as airports and hospitals.

Chaiechi, Wong and Tavares compare the urban and economic patterns of two MNG models as evidenced through the tropical cities of Singapore and Cairns. They highlight different urban growth patterns and assess whether planning strategies in these cities have efficiently improved the quality of life for the people. Cairns is a sprawling regional city in northeast Queensland far away from Australia's main urban centres such as the state's southern capital, Brisbane, and other metropolises further in the temperate south. The city is characterised by a strong tourism and hospitality economy and its growth model is based on low-rise developments widespread throughout the city, despite Cairn's small population. On the other hand, Singapore is a small island city-state with the second highest population density in the world. It is 
eTropic 19.2 (2020) Special Issue: Sustainable Tropical Urbanism

situated near the equator in Southeast Asia and has very limited natural resources, including a lack of land. Yet, despite these constrained circumstances, Singapore has emerged as a leader in urban planning and design and is currently taking the lead towards urban sustainability. The authors review ongoing developmental projects in Singapore to show how urban development and economic growth are not always related. They also emphasise the importance of the happiness and welfare of the city's people in any consideration of development. Through this comparative analysis of two tropical cities the authors show how cities can grow following a wide variety of urban models. They suggest that analysing those different models allows us to identify relevant economic growth factors and can help in demystifying the relationship between urbanisation and local economic growth.

\section{Land Reclamation, Sand and Migrant Labour - Singapore}

In the paper "Singapore 'A Land Imagined': Rising Seas, Land Reclamation and the Tropical Film-Noir City" we are taken on a journey into cinematic landscapes to explore the very foundations that uphold the global city of Singapore. Through film ethnography, Anita Lundberg and Jasmin Thamima Peer (2020) reveal the city's land reclamation, sand importation and migrant construction labourer practices. As in the previous paper, this discussion highlights how the continuing growth of this futuristic city is strongly entwined with economic development - but is furthermore entangled with social and cultural aspirations for the 'Singapore Dream'. The authors open their paper by framing it within climate change impacts on Singapore and the threat of rising sea levels. Again we are reminded, as per previous papers, that the Tropics and geography are important. Singapore, as a low lying urban island in the equatorial AsiaPacific, is predicted to be particularly impacted by higher-than-global-average sea rise and intensities of the El Niño Southern Oscillation (ENSO) leading to sporadic heavy rainfall, tropical storm surges and risks of extreme flooding. A priority of the Singapore government's Climate Action Plan is the protection of the island's coastline from inundation with a long-term view into the next century. Singapore's future developmental vision for a resilient city and its continued economic prosperity includes further extensive land reclamation projects to protect vulnerable areas around the coastline through poldering projects and the reclaiming of offshore islands joined-up with barrages, to create new land and freshwater reservoirs. However, as Lundberg and Peer note, "despite this awe-inspiring imagining, the land reclamation and construction projects to create this city of the future will still rely on the labour of migrants" (2020, p. 221).

The authors alert the reader to the unsustainable practices that lie hidden beneath land reclamation projects with their reliance on sand imports and the cheap labour of migrants from the Asia-Pacific region. Taking an historical view, they note how land 
eTropic 19.2 (2020) Special Issue: Sustainable Tropical Urbanism

reclamation, from British Colonial times through early independence and into the postcolonial period, has been strongly associated with the city's development. Thus future visions for the city are not neutral, but are socially and cultural linked with technocracies of the 'Singapore Dream'. Through a close ethnographic reading of the film A Land Imagined by Singaporean director Yeo Siew Hua, combined with analysis of film interviews, multidisciplinary academic literature and technical reports, the authors unearth the unsustainable practices involved in land reclamation. They point out that land is not reclaimed from the sovereign sea, as is popularly imagined; rather, sand is imported from surrounding countries in Southeast Asia, and its extraction through mining and dredging from rivers and seas leads to severe environmental degradation. The enormous and lucrative trade in sand is embedded within capitalist globalisation and neoliberal practices - the same practices that incorporate migrant construction labourers who work on land reclamation projects under restrained conditions. These conditions are revealed through the cinematic and narrative devices of $A$ Land Imagined. A tropical-noir mystery thriller filmed during the monsoon, the story follows the rhizomatic path of a detective and his police partner as they try to uncover the disappearance of two construction workers - one from Bangladesh and the other from China. Interwoven within the film is an exposé and critique of migrant labour conditions and a commentary on the unsustainable social costs and inequalities buried within the construction of the 'Singapore Dream'.

\section{Vertical Urban Farming - Singapore}

In land-scarce Singapore with its vertically constructed urban environment and dense population, food production is of critical concern. While the country has demonstrated its ability to provide a diverse supply of food - $90 \%$ of which is imported from other countries - the COVID-19 global pandemic has further exposed Singapore's vulnerability to external shocks that affect international food supply chains and, in turn, Singapore's food security.

In their paper, "Vertical Farming: An Assessment of Singapore City", Jacob Wood, Caroline Wong and Swathi Paturi (2020) explore current practices of Singapore urban farming, focusing specifically on vertical farming and government support for these initiatives. Additionally, they further analyse challenges and opportunities of Singapore's urban farming model and its transferability to other cities, particularly with tropical environments. In 2019, the Environment and Water Resources Ministry announced the ambitious " 30 by 30 " goal aiming to produce 30 percent of Singapore's nutritional needs locally by 2030 and calling for new solutions to raise productivity. Innovative approaches such as hydroponics, aeroponics, aquaponics, and greenhouses can be used to overcome not only food safety and land resource issues, but also better manage the threats posed by rapid urbanisation. The authors' review 
eTropic 19.2 (2020) Special Issue: Sustainable Tropical Urbanism

significant public and private investment in this emerging field, identifying efforts starting with community gardens, then citizen farms, and rooftop farming, before finally venturing into large scale commercial production. Despite a highly constrained urban environment where land scarcity is exacerbated by a complex regulatory land use framework, Singapore has so far achieved developments that may provide a valuable guide for other cities aspiring to grow their vertical farming capabilities.

\section{Re-thinking Urban Planning for Active Aging - Singapore}

The world's population aged 60 years or over numbered 962 million in 2017, more than twice as large as in 1980. And this number is projected to reach nearly 2.1 billion by 2050 (UN, 2017). In the final paper of this Special Issue, André Siew-Yeong Yew brings us to a future tropical scenario in which he explores the needs of projected silver generations in Singapore. Specifically, the paper analyses the contexts of living, working, and playing for Singapore's population over the age of 65 by 2050. In his piece "Re-thinking Urban Planning for Singapore's Extended Lifespan Population of 2050: A League of Its Own" (2020), Yew identifies gaps in Singapore's urban planning for betterment in aging and highlights the requirements for enhancing active and healthy aging strategies. Indeed, in Singapore, the number of elderly aged 65 and over is almost matching that of youths aged 14 and below. The proportion of elderly residents aged 65 years and over among the resident population has seen a $6 \%$ increase over the last decade from $8.8 \%$ in 2009 to $14.4 \%$ in 2019 (Singapore Department of Statistics, 2019). While life expectancy will rise further over the next decades, fertility rates have been gradually declining. Thus, making Singapore more senior-friendly has become a necessary and logical response to keep the city vibrant and active and to promote the wellbeing of its older urban residents without affecting its economic growth prospects.

This paper also provides a critical analysis of the United Nations Sustainable Development Goals and the World Health Organization's Healthy Aging and Age Friendly Environment policy frameworks, demonstrating that while they provide comprehensive global standards, the Singapore situation requires a unique set of criteria for its people. Yew argues in the overview to his paper, that "Singapore's current 65 and over population is not the typical aging population, but one characterised by an extended lifespan with autonomy, employability, and vitality" (2020, p. 249). The paper articulates that each generation of an aging population will necessitate unique sets of urban planning criteria and concludes by identifying a specific set of criteria for the 'Singapore Extended Lifespan Population (SELP)' that fits Singapore's aging population needs and covers different aspects of living, working, and playing which differ from those emphasised in the global frameworks of the UN and $\mathrm{WHO}$. 
eTropic 19.2 (2020) Special Issue: Sustainable Tropical Urbanism

\section{Conclusion: Towards Sustainable Tropical Urbanism}

Sustainable Tropical Urbanism calls for participatory approaches in urban analysis and urban design. The papers brought together in this Special Issue go towards this practice, drawing together academics and practitioners from urban planning and design, architecture, economics, business, geography, anthropology, creative industries, arts and culture; with expertise in human settlements, urban ethnography, Indigenous community, urban landscape, cultural-ecological landscapes, architectural history and heritage, heritage conservation, building and city science, risk management, disaster resilience, food sustainability, environmental and climate change issues and sustainable development. The idea for the collection began with an interdisciplinary forum on Sustainable Tropical Urbanism in Singapore in September 2019, which also included contributions from practicing planners and architects who could 'reality check' a shared vision of Sustainable Tropical Urbanism and enable critical reflection on wicked problems like climate change, resource constraints and uneven urban development. Our inclusion of multiple academic disciplines as well as relevant practical expertise reflects a larger movement toward co-producing knowledge for the sustainable city (Polk, 2020). The problems of sustainable urban development in the tropical world require new knowledge networks for sharing and learning, critical reflection on barriers to change in conversation with policy makers, and breaking apart the compartmentalisation of academic and other knowledges to bring about change. This should furthermore be placed within cross cultural dialogues between peoples of the Tropics.

The papers collected here shed light on a more plural approach to sustainabilities, and highlight the strategic role played by urban planning and design in the building of future sustainable tropical cities. Collectively they address the following questions:

- How can we build tropical cities that are resilient to climate change?

- How can we reduce impacts on the vulnerable in rapidly urbanising environments?

- What are the best sustainable urbanism tools and practices that can be implemented and shared, and what kind of networks are necessary?

- How can we ensure that planning processes are place-based and respect their unique culture and character?

Our aim is to inspire further conversation and debate about tropical cities, which are often subsumed under larger conversations about urban sustainability despite the important differences. The World Cities Report 2020 fails to mention the tropics at all in its expansive undertaking to present evidence and policy analysis across extensive 
eTropic 19.2 (2020) Special Issue: Sustainable Tropical Urbanism

domains, including chapters on economy, environments, governance, technology, inclusivity and people. Likewise, the report does not address the notion of place, which we have argued is intimately entwined with people and urban pasts, presents, and future prospects. While the UN-Habitiat report rightly asserts that "the intrinsic value of sustainable urbanization can and should be harnessed for the wellbeing of all" (UNHabitat, 2020), the specific dynamics of tropical regional climates, environments, cultures, lifestyles and the meanings people attach to place are not represented. Also of note is the report's focus on sustainable urbanisation, which is different to our emphasis here on urbanism. Urbanisation is to emphasise the results; while urbanism concentrates on the tools and means that enable the implementation of sustainable urbanisation. In the Tropics there is urgent work to be done in the sharing of knowledge to address the specific circumstances and issues facing tropical regions as well as the tropics worldwide. This knowledge sharing is essential preparedness for achieving appropriate sustainable urbanisation.

This Special Issue of eTropic opens up a space to discuss these many challenges of sustainable urbanisation in the Tropics. The issue has clustered the various topics under several themes addressing resources, local frameworks and different urban design and planning approaches. The works are in variety, ranging across topics, viewing them through different lenses, informed by different theoretical and disciplinary approaches and employing different methodologies. There is more urgent work needed to explain, explore, and to further advance the understanding of the dynamics of the Tropics and tropical sustainabilities. While a single journal issue cannot do justice to the vast challenges and opportunities pertaining to tropical urbanism, this Special Issue is designed to provide key insights as a step towards further theory and practice. It has concentrated on the monsoonal Asia-Pacific in order to better draw out the similarities, while respecting the differences, towards a concept of Sustainable Tropical Urbanism. 
eTropic 19.2 (2020) Special Issue: Sustainable Tropical Urbanism

\section{References}

Al Mamun, M., Paul, P., Noor, S., \& Begum, A.A. (2020). Reviving the Urban Water-Edge: History and Heritage Morphology in the Envisaging of Chittagong City. eTropic: electronic journal of studies in the tropics, 19 (2), 97-118. http://dx.doi.org/10.25120/etropic.19.2.2020.3775

Amin, S. (2006). The Millennium Development Goals: A Critique from the South. Monthly Review, 57(10), 1-15. https://doi.org/10.14452/MR-057-10-2006-03 1

Azzali S. (2019). Mega sporting events and their impact on the built environment: lessons learned from the past. A|Z ITU Journal of the Faculty of Architecture, 16(2), 25-37.

Burby, R.J. (2003). Making Plans that Matter: Citizen Involvement and Government Action. Journal of the American Planning Association, 69(1), 33-49. https://doi.org/10.1080/01944360308976292

Castles, A. (2020). Community Initiated Adaptive Reuse for Culture and the Arts: 'The Tanks Arts Centre' Cairns, Australia. eTropic: electronic journal of studies in the tropics, 19 (2), 119-142. http://dx.doi.org/10.25120/etropic.19.2.2020.3740

Chaiechi, T. (2020). Sustainable Tropical Cities: A Scoping Review of Multidisciplinary Methods for Urban Planning. eTropic: electronic journal of studies in the tropics, 19 (2), 25-51. http://dx.doi.org/10.25120/etropic.19.2.2020.3743

Chaiechi T., Wong, C. \& Tavares S. (2020). Urban Design and Economic Growth: An Analytical Tale of Two Tropical Cities. eTropic: electronic journal of studies in the tropics, 19 (2), 172-200. http://dx.doi.org/10.25120/etropic.19.2.2020.3741

Furlan, R., \& Petruccioli, A. (2016). Affordable Housing for Middle Income Expats in Qatar: Strategies for Implementing Livability and Built Form. ArchNet IJAR: International Journal of Architectural Research, 10(3), 138-151.

Gehl, J. (2010). Cities for People. IslandPress

Gibson, K., Astuti, R., Carnegie, M., Chalernphon, A., Dombroski, K., Haryani, A.R., Hill, A., Kehi, B., Law, L., Lyne, I., McGregor, A., McKinnon, K., McWilliam, A., Miller, F., Ngin, C., Occeña-Gutierrez, D., Palmer, L., Placino, P., Rampengan, M., Than Wynn, L., Wianti Nur, I., \& Wright, S. (2018). Community economies in Monsoon Asia: Keywords and key reflections. Asia Pacific Viewpoint, 59(1), 3-16. https://doi.org/10.1111/apv.12186

Gibson-Graham, J.K., Hill, A., \& Law, L. (2016). Re-embedding economies in ecologies: resilience-building in more than human communities. Building Research \& Information, 44(7), 703-716. https://doi.org/10.1080/09613218.2016.1213059

Giridharana, R., \& Emmanuel, R. (2018). The impact of urban compactness, comfort strategies and energy consumption on tropical urban heat island intensity: A review. Sustainable Cities and Society 40, 677-687 https://doi.org/10.1016/j.scs.2018.01.024

Islam, M., \& Muntasir, H. (2020). Tropicality of Colonial Heritage Buildings in a Deltaic Landscape: British Colonial Architecture in Khulna. eTropic: electronic journal of studies in the tropics, 19(2), 72-96. http://dx.doi.org/10.25120/etropic.19.2.2020.3762

Law, L., \& Musso, U. (2020). Towards a Tropical Urbanism for Cairns, Australia. eTropic: electronic journal of studies in the tropics, 19(2), 52-71. http://dx.doi.org/10.25120/etropic.19.2.2020.3774

Law, L., Safarova, S., Campbell, A., \& Halawa, E. (in press). Design for liveability in tropical Australia. In Wallace, R., Harwood, S., Gerritsen, R., Prideaux, B., Brewer, T., Rosenman, L., Dale, A. (Eds). Leading from the North: Rethinking Northern Australia Development. ANU Press.

Lindley, S., Pauleit, S., Yeshitela, K., Cilliers, S., \& Shackleton, C. (2018). Rethinking urban green infrastructure and ecosystem services from the perspective of sub-Saharan 
eTropic 19.2 (2020) Special Issue: Sustainable Tropical Urbanism

African cities, Landscape and Urban Planning, 180, 328-338.

https://doi.org/10.1016/j.landurbplan.2018.08.016

Lundberg, A. (2020). Balinese Dancer wearing a Gas Mask: Climate Change and the Tropical Imaginary. [COP26 Perspectives Special Issue]. Scottish Geographical Journal RSGJ, 136 (1-4). https://doi.org/10.1080/14702541.2020.1858589

Lundberg, A. (2018). Living Cities: Tropical Imaginaries. eTropic: electronic journal of studies in the tropics, 17(1), 1-5. http://dx.doi.org/10.25120/etropic.17.1.2018.3638

Lundberg, A., \& Peer, J.T. (2020). Singapore 'A Land Imagined': Rising Seas, Land Reclamation and the Tropical Film-Noir City. eTropic: electronic journal of studies in the tropics, 19(2), 201-227. http://dx.doi.org/10.25120/etropic.19.2.2020.3739

Nutsford, D., Pearson, A., \& Kingham, S. (2017). An ecological study investigating the association between access to urban green space and mental health. Public Health, 127(11), 1005-1011. https://doi.org/10.1016/..puhe.2013.08.016

Oppermann, E.,M., Law, L., Smith, J.A., Clough, A. \& Zander, K. (2017). Heat, Humidity and Health in Australia's Tropical Monsoon Zone: A critical review of heat stress in a changing climate'. WIREs Climate Change, 8(4),1-23 https://doi.org/10.1002/wcc.468

Petruccioli, A. (2007). After Amnesia: Learning from the Islamic Mediterranean Urban Fabric. Dipartimento di Ingegneria Civile e Architettura - Politecnico di Bari.

Polk, M. (Ed.). (2020). Co-producing Knowledge for Sustainable Cities: Joining Forces for Change, (2nd ed.). Routledge.

Safarova, S., Halawa, E., Campbell, A., Law, L., \& van Hoof, J. (2018). Pathways for Optimal Provision of Thermal Comfort and Sustainability of Residential Housing in Hot and Humid Tropics: A critical review. Indoor and Built Environment, 27(8):1022-1040.

Singapore Department of Statistics (2019). Department of Statistics Singapore https://www.singstat.gov.sg/

Song, X.P, Tan, P.Y, Edwards, P., \& Richards, D. (2018). The economic benefits and costs of trees in urban forest stewardship: A systematic review, Urban Forestry \& Urban Greening, 29, 162-170 https://doi.org/10.1016/j.ufug.2017.11.017

Sultana, F. (2018). An(Other) geographical critique of development and SDGs. Dialogues in Human Geography 8(2), https://doi.org/10.1177/2043820618780788

UN-Habitat. (2020). World Cities Report 2020: The Value of Sustainable Urbanization. https://unhabitat.org/World\%20Cities\%20Report\%202020

United Nations. (2017). The New Urban Agenda. Habitat. https://habitat3.org/the-new-urbanagendal

United Nations. (2017). World Population Ageing. Highlights. https://www.un.org/en/development/desa/population/publications/pdf/ageing/WPA201 7 Highlights.pdf

United Nations. (2015a). Transforming our world: the 2030 Agenda for Sustainable Development. Sustainable Development Goals. https://sustainabledevelopment.un.org/post2015/transformingourworld

United Nations. (2015b). The 17 Goals. United Nations. Department of Economic and Social Affairs. Sustainable Development. https://sdgs.un.org/goals

Wood, J., Wong, C., \& Paturi, S. (2020). Vertical Farming: An Assessment of Singapore City. eTropic: electronic journal of studies in the tropics, 19(2), 228-248. http://dx.doi.org/10.25120/etropic.19.2.2020.3745

Yew, A.S.Y. (2020). Re-thinking Urban Planning for Singapore's Extended Lifespan Population of 2050: A League of its Own. eTropic: electronic journal of studies in the tropics, 19(2), 249-273. http://dx.doi.org/10.25120/etropic.19.2.2020.3744

Yulia, Y., \& Arlianda, R. (2020). Climate Resilience and Policy Transfer in Semarang City, Indonesia. eTropic: electronic journal of studies in the tropics, 19(2), 143-171. http://dx.doi.org/10.25120/etropic.19.2.2020.3767 
eTropic 19.2 (2020) Special Issue: Sustainable Tropical Urbanism

Dr Simona Azzali is a researcher in urban design at the Singapore campus of James Cook University where she coordinates the Master of Planning and Urban Design and teaches core, elective, and studio modules on disaster management, urban research methods, urban design and sustainable urbanism. She is a member of JCU's Tropical Urbanism and Design Lab (TUDLab), and JCU's Centre for International Trade and Business in Asia (CITBA). Simona is passionate about cities and is a strong advocate for people-oriented and participatory design approaches to build better cities. She has worked and researched for various renowned academic institutions, such as the National University of Singapore, UCL London, Politecnico di Milano, and Qatar University.

Associate Professor Lisa Law is an interdisciplinary researcher with a background in geography and urban studies. Her research focuses on urban spaces in Southeast Asia and tropical Australia, and crosses a wide spectrum including: liveability and place-based urban design for the tropics, the meanings and uses of public space, environmentally responsive design and the role of culture and the arts in place making. She is founder of James Cook University's Tropical Urbanism and Design Lab, an interdisciplinary team of geographers, architects, sociologists and planners interested in urbanism in the tropics. Prior to commencing her appointment at James Cook University, she was employed at the Australian National University, the University of Western Sydney, the National University of Singapore and the University of St Andrews in Scotland.

Associate Professor Anita Lundberg is a cultural anthropologist. Her ethnographies have explored everyday urban life, the cinematic city, and neoliberal higher education in Singapore; climate change street art in Bali; the architecture of a Malay house and garden of indigenous trees; and a whale hunting village in Indonesia. Anita has won awards and held international fellowships: LIA TransOceanik (CNRS, JCU, Collége de France); The Cairns Institute (TCl); Evans Fellow, Cambridge University, UK; Guest Researcher, Maison Asie-Pacifique, Université de Provence, France; Visiting Fellow, Institute of the Malay World and Civilization, National University Malaysia; and Anthropologist-in-Residence, Rimbun Dahan, Malaysia. She has curated exhibitions in NY, LA, Paris and Sydney, and her own research has been exhibited at the Australian National Maritime Museum, the National Art Gallery of Malaysia and Alliance de Française. Anita was a Post-Doctoral Fellow, Cambridge University, UK, she has a PhD in Anthropology, and an MA in Science \& Technology Studies. 